\title{
A study on molecular surveillance of Theileria spp. infection and its impact on hematological and biochemical changes in naturally infected small ruminants at Multan, Pakistan
}

\author{
Muhammad Riaz ${ }^{*}$ and Zahida Tasawar \\ Zoology Division, Institute of Pure and Applied Biology, Bahauddin Zakariya University, Multan 60800-Pakistan \\ *Corresponding author's email: mriaz_sabri@yahoo.com \\ Citation \\ Muhammad Riaz and Zahida Tasawar. A study on molecular surveillance of Theileria spp. infection and its impact \\ on hematological and biochemical changes in naturally infected small ruminants at Multan, Pakistan. Pure and \\ Applied Biology. Vol. 6, Issue 4, pp1427-1435. http://dx.doi.org/10.19045/bspab.2017.600154
}

\begin{tabular}{llll}
\hline \hline Received: 27/07/2017 & Revised: 19/10/2017 & Accepted: 24/11/2017 & Online First: 30/11/2017 \\
\hline \hline
\end{tabular}

\section{Abstract}

The current investigation was conducted to evaluate hematological and biochemical changes in naturally infected sheep and goats with Theileria spp. infection and to compare the conventional microscopic method of diagnosis with PCR amplification. A total of 200 blood samples (144 sheep and 56 goats) were collected and examined for the presence of Theileria infection. 12.5\% and $39.5 \%$ blood samples were found positive with Theileria infection by microscopic examination and PCR amplification respectively. Hematological parameters were analyzed by automatic hematology analyzer (Diatron Abacus) while serum biochemistry was studied by Semi-automatic Chemistry Analyzer (Micro Lab 300). Hematological parameters revealed significant ( $p<0.05)$ decrease in RBCs counts, $\mathrm{Hb}$ contents, $\mathrm{PCV}, \mathrm{MCH}$ and $\mathrm{MCHC}$ values while non-significant ( $\mathrm{p}>$ 0.05) correlation in MCV values of Theileria infected small ruminants. Biochemical analysis revealed significant $(\mathrm{p}<0.05)$ reduction in total serum protein and albumin concentration while non-significant $(p>0.05)$ rise in urea and cholesterol level in infected animals compared to normal. Theileria piroplasms prevalence during early stage of disease without any clinical symptoms can only be identified through PCR amplification compared to microscopic examination.

Keywords: Hemato-biochemical values; Pakistan; PCR; Small ruminants; Theileria infection

Introduction
Theileriosis caused due to Theileria spp. (Piroplasmida, Theileridae) is a tick-borne protozoan disease found both in wild and domestic ruminants. Theileria genus belongs to Apicomplexa phylum including Babesia, Toxoplasma, Neospora, Plasmodium and others [1]. Theileriosis transmitted by ticks, caused high morbidity and mortality in infected animals resulted in higher economic losses in tropical and subtropical regions of the world $[2,3]$. A total of six Theileria species caused ovine and caprine theileriosis from which Theileria lestoquardi considered highly pathogenic while $T$. ovis caused subclinical infection in sheep and goats [4]. 
Theileria infection can be acute, subacute or chronic. Malignant ovine theileriosis (MOT) caused due to $T$. lestoquardi infection resulted in higher mortality in sheep and goats [3], 100\% mortalities had been reported in case of malignant ovine theileriosis [5]. Theileria lestoquardi causes fever, emaciation, lymphadenopathy, wasting, malaise anorexia, rapid heartbeat, dyspnea, listlessness, anemia, icterus, jaundice, pyrexia, intermittent diarrhea or constipation, weakness and termination of rumination [6]. During theileriosis, Theileria schizonts are frequently observed in liver, spleen, lungs, kidneys and lymph nodes [7]. Clinical symptoms of theileriosis could be electrolyte imbalance, overdosing with calcium, digoxin, and cardiomyopathy [8].

The diagnosis of Theileria spp. in general is based on microscopy of stained smears and presence of clinical based symptoms in animals infected with ovine theileriosis. But the above cited methods are beneficial only in acute cases of theileriosis and insufficient for detection of piroplasms in carrier animals [9, 10]. In recent years, the molecular technique Polymerase chain reaction (PCR) is frequently used for detection of ovine and caprine piroplasms. Hematobiochemical indices had been employed in attempts to get information regarding health status, performance and fitness of animals. An aberration from normal values might serve a guide for the differential diagnosis of a disease status [11]. Blood glucose and albumin level reduced significantly while serum protein and creatinine level decreased non-significantly during theileriosis [12]. Biochemical profile of Theileria infected animals showed higher level of urea, aspartate amino transferase, bilirubin (end product of hemoglobin) level and lactate dehydrogenase compared to healthy animals
[13]. The significant decrease in RBCs counts, $\mathrm{Hb}$ contents and PCV values were identified while no changes found in $\mathrm{MCH}$ and MCHC values in infected goats with theileriosis [14]. Hematobiochemical changes reported in earlier studies in infected small ruminants was based on experimental animals, the current investigations was designed to delineate hematobiochemical changes in naturally infected small ruminants with theileriosis which can be utilized for diagnosis, prognosis and for better management of metabolic health status of infected animals.

\section{Materials and methods Study area}

Multan is situated in Punjab province (southern region), Pakistan between 29'22'north latitude and 71'-4' east longitude, higher temperature $49^{\circ} \mathrm{C}$ during hotter season and $1^{\circ} \mathrm{C}$ during winter season. The average rainfall in district Multan is of $127 \mathrm{~mm}$. The present survey was conducted on Theileria spp. infection and changes in hematological and biochemical values in Theileria infected small ruminants in Multan (Figure 1).

\section{Blood sampling}

200 blood samples ( sheep $=144$, goats $=56$ ) were collected from apparently healthy small ruminants from selected herds located at different places during 2013. 10 milliliter (ml) blood was collected from sampled animals by puncturing jugular vein with sterilized syringe. $5 \mathrm{ml}$ collected blood was poured in eppendorf having few drops of EDTA for extraction of DNA for PCR amplification; while other $5 \mathrm{ml}$ collected blood was used for serum collection in order to determine hematobiochemical analysis. The collected blood samples were properly labeled including date, location and characteristics of animals as well as herds. 


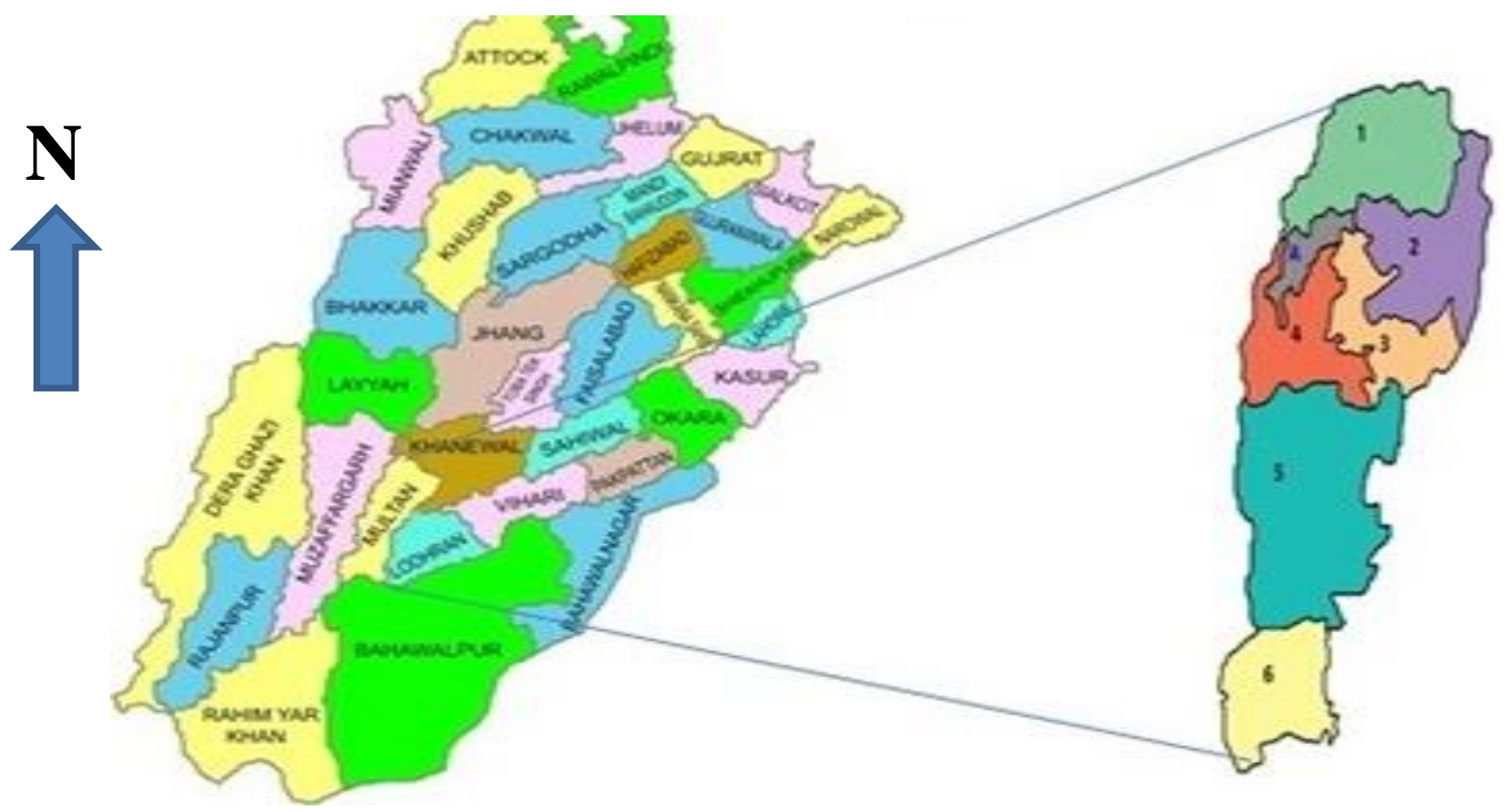

Figure 1. Study area of district Multan, Punjab, Pakistan

\section{Microscopic examination}

Thin blood smears were prepared in the field, then air dried and fixed in methanol (absolute) for 1 minute in the field. The blood smears were stained with Giemsa $(5 \%)$ for 30 minutes in the laboratory and enquired Theileria spp. under immersion oil lens $(\times$ 1000). 250 microscopic fields were surveyed to identify the infected RBCs in order to assess the parasitemia ratio in the infected animals [15].

\section{PCR amplification}

Inorganic method was used for DNA extraction [16]. The quality of extracted DNA was evaluated by spectrophotometer analysis at 260/280 $\mathrm{nm}$ density constant and gel electrophoresis. The extracted DNA was used for PCR amplification. The primers set 989 F; 5'-AGTTTCTGACCTATCAG-3' and 990 R; 5'-TTGCCTTAAACTTCCTTG-3' (Penicon) were used for amplification of 1098 bp portion of the ssu rRNA gene of genus Theileria. The final $50 \mu 1$ PCR mixture contained of $5 \mu \mathrm{l}\left(1 \mathrm{ng} \mu \mathrm{l}^{-1)}\right.$ of template DNA, $5 \mu \mathrm{l}$ of $10 \mathrm{X}$ PCR buffer (100 mMTris- $\mathrm{HCl}$ (pH 9) $500 \mathrm{mMKCl}, 1 \%$ Triton X-100), $5 \mu \mathrm{l}$ of $50 \mathrm{Mm} \mathrm{MgCl} 2,6 \mu \mathrm{l}$ of dNTPs, $4 \mu \mathrm{l}$ of each primer $(\mu \mathrm{M})$ (Penicon) at a concentration of $10 \mathrm{pmol} / \mu \mathrm{l}, 2 \mathrm{U}$ of Taq DNA polymerase (Vivintas) and $20.5 \mu \mathrm{l}$ of PCR water. PCR amplification was done using a programmable thermal cycler (BIORAD). The cyclic conditions were at $94{ }^{\circ} \mathrm{C}$ for $5 \mathrm{~min}$ (initial denaturing step), followed by 35 cycles each at $94{ }^{\circ} \mathrm{C}$ for $1 \mathrm{~min}$ (denaturing step), at $60{ }^{\circ} \mathrm{C}$ for $1 \mathrm{~min}$ (annealing step) and $72{ }^{\circ} \mathrm{C}$ for $1 \mathrm{~min}$ (extension step) with a final extension step at $72{ }^{\circ} \mathrm{C}$ for $7 \mathrm{~min}$. PCR amplified products were separated on $1.5 \%$ solidified agarose gel in TBE buffer and visualized by using ethidium bromide and UV-illuminator. The 100-1500 bp ladder (Vivantus) was used as DNA marker. Positive control genomic DNA of Theileria was provided by Professor Urike Seitzer (VIIRC, Borstel, Germany).

\section{Haematological and Serum biochemical studies}

The haematological values such as RBCs, WBCs, HB concentration, PCV, MCV, MCH and $\mathrm{MCHC}$ values were recorded of infected and healthy small ruminants. The sera of 
infected and healthy animals were analyzed for the measuring of total protein, albumin, globulins, cholesterol, calcitonin and urea level using commercial test kits.

\section{Statistical analysis}

Mini Tab (Version 16) was used for statistical analysis. One way Analysis of Variance (ANOVA) was used to compare and determine significant difference of hematological and biochemical parameters of laboratory obtained values between healthy and infected animals with theileriosis. All values were expressed as mean and standard error (SE). Fisher's exact test and Pearson's Chi square test was used to find association between different variables of (animals and herds) and ovine theileriosis. A $p<0.05$ value was considered as statistically significant

\section{Results and discussion}

Blood smear examination and clinical symptoms based diagnosis are useful in acute cases but meager in subclinical cases of theileriosis. As opponent to these methods, molecular assays are better for detection of piroplasms in carrier animals. PCR amplification method is more specific and sensitive than microscopy for diagnosis of Theileria piroplasms. A total of $12.5 \%$ and $39.5 \%$ blood samples found Theileria infected by microscopy and PCR respectively during present study. The sampling area, number of samples collected and Theileria positive samples are described in detail (Table 1).

Table 1. Microscopic examination of thin blood smears and PCR amplification results of sheep and goats from Multan, Pakistan

\begin{tabular}{|c|c|c|c|c|c|c|}
\hline Area & \multicolumn{2}{|c|}{ No. of samples } & \multicolumn{4}{c|}{ Test } \\
\hline & & Microscopic examination & \multicolumn{2}{c|}{ PCR Examination } & \\
\hline & & Positive & $\%$ & Positive & $\%$ & P*value \\
\hline Basti Mongwad & 25 & 3 & 12 & 7 & 28 & \\
\hline Basti Lotahar & 30 & 5 & 16.7 & 20 & 66.7 & \\
\hline Basti Aladad & 25 & 3 & 12 & 5 & 20 & \\
\hline Basti Shhadan lund & 30 & 4 & 13.3 & 10 & 33.3 & \\
\hline Maza Tatypur & 50 & 8 & 16 & 27 & 54 & \\
Moza Karnalpur & 40 & 2 & 5 & 10 & 25 & $0.000^{\text {b*** }}$ \\
\hline Total & 200 & 25 & 12.5 & 79 & 39.5 & $0.000^{\text {a*** }}$ \\
\hline
\end{tabular}

$\mathrm{a}=$ Fisher's exact test $\mathrm{b}=$ Chi square test;

$\mathrm{P}<0.01=$ Significant $(* *) ; \mathrm{P}<0.001=$ Highly significant $(* * *)$

The higher prevalence of Theileria spp. was identified in Basti Lotahar (66.7\%) while the lowest in Basti Allah dad (20\%) based on PCR amplification (Figure 2). Chi square results indicated significant correlation of ovine theileriosis between different sampling sites $(\mathrm{p}<0.05)$.

The hematobiochemical profile is a significant tool to distinguish between healthy and diseased animals in veterinary studies. The results of present study shown ovine Theileria infection led to alterations in some hematobiochemical parameters (Table
$2 \& 3)$. The significant $(\mathrm{p}<0.05)$ decrease in RBCs counts, $\mathrm{Hb}$ contents and PCV values was found between normal and Theileria infected animals. Lower RBCs count, $\mathrm{Hb}$ contents and PCV had been found in Theileria infected small ruminants which are in accordance to present study [17-19]. Cattle infected with Theileria annuluta also shown decline in RBCs count, Hb contents and PCV values [20, 21]. The lower hematological values in animals with clinical signs suggest a benign microcytic and hyperchronic anemia. Extensive 
hemorrhages, abdominal ulcers and insistence of parasitic stages in erythrocyte lead to lower hematological values [22]. This stress might attribute erythrocytic fragility because of membrane lysis and lower haemoglobin concentration in infected animals $[23,24]$. The decline of RBCs count, $\mathrm{Hb}$ contents and PCV values might endorsed the deficit of erythrocytes resulted by invasion of macrophages in lymph nodes, spleen and other organs of reticuloendothelial system. The oxidative stress increased in infected animals cannot be abridged by the antioxidant enzymetic activity [25]. The decline in RBCs count and HB contents was due to higher parasitaemia level in the infected small ruminants [26] and led to severe anemia in the Theileria spp. infected animals [27]. Surface membrane changes, increase the osmotic fragility and variations of glycoloipids of red blood cells membrane and oxidative damages resulted in anemia in diseased animals $[28,29]$. Destruction of
RBCs counts during anemia in infected animals might be due to fastening of autoantibody to infected RBCs which later phagocytized [30] or due to cytokine tumor necrosis factor (TNF 1$)$ which is effective inducer of fever and might play a role in development of anemia [31]. Removal of piroplasms from infected erythrocytes by macrophages could be the source of anemia in the Theileria infected animals [32]. The reduction in RBCs count might be due to erythropagocytosis during theileriosis and resulted in higher oxygen radicals caused anemia [29].

During present study, lower values of MCV found between healthy and Theileria spp. infected animals. Similar trend of significantly $(\mathrm{p}<0.05)$ higher $\mathrm{MCV}$ value was found during malignant ovine and bovine theileriosis [13]. Concerning the erythrocyte indices with parasitemia rates a significant depletion in MCV value [17].

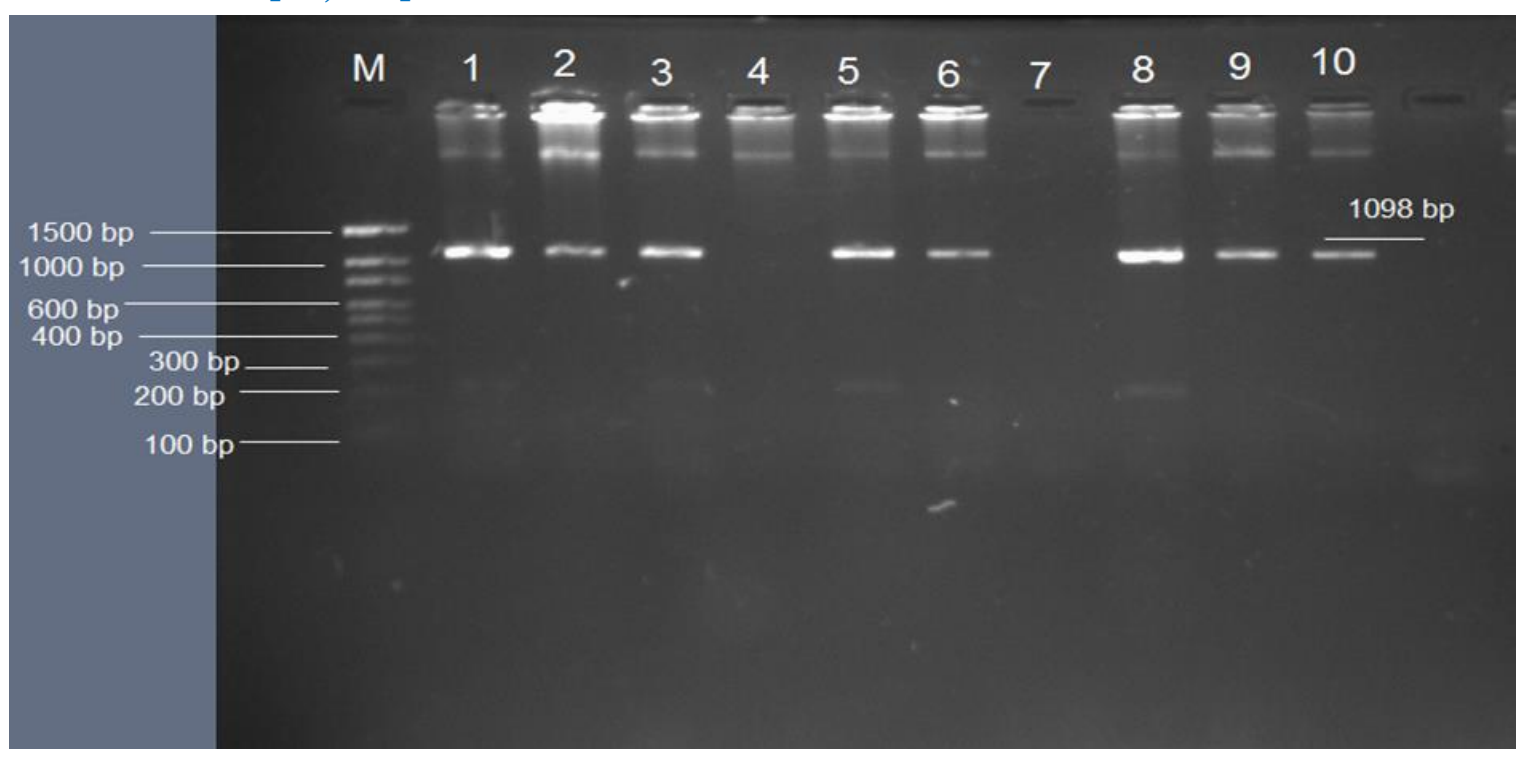

Figure 2. Agarose gel electrophoresis of amplified PCR products obtained from Theileria species genomic DNA using Theileria specific primers. Lane M. DNA marker of 100, 1500bp; Lane 1. Theileria species DNA positive control; $\quad$ Lane 4. Theileria species Negative control (Distilled water); Lane 2.3.5.6.8.9.10. Theileria species positive samples: Lane 7. Theileria species negative samples 
Significant $(\mathrm{p}<0.05)$ decreases were found in $\mathrm{MCH}$ and $\mathrm{MCHC}$ values in the animal infected with ovine theileriosis. Hematological analysis revealed significant increase $(\mathrm{p}<0.05)$ in WBCs count in infected small ruminants compared with healthy animals. The higher erythrocytes had been found in sheep infected with Theileria spp. compared with control group [33, 34] but contradicts to that of [35] who showed nonsignificant leukocytosis in animals experimentally infected with Theileria spp. infection which might be due to proliferation of lymphocytes as defensive retort to attacking parasite.

Table. 2. Mean values of hematological parameters in affected and apparently healthy small ruminants

\begin{tabular}{|c|c|c|c|}
\hline S. No. & Parameters & Normal Group $(\mathbf{n}=100)$ & Infected Group $(\mathbf{n}=\mathbf{5 0})$ \\
\hline 1 & $\mathrm{WBC} \times 10^{3} / \mu \mathrm{L}$ & $31.8 \pm 1.55$ & $38.1 \pm 1.65^{* * * *}$ \\
\hline 2 & $\mathrm{RBC} \times 106 / \mu \mathrm{L}$ & $6.31 \pm 0.12$ & $5.9 \pm 0.33$ \\
\hline 3 & $\mathrm{HGB} \mathrm{g/dL}$ & $7.4 \pm 0.12$ & $7.1 \pm 0.12^{* * *}$ \\
\hline 4 & $\mathrm{PCV} \%$ & $26.8 \pm 0.60$ & $16.4 \pm 0.98^{* * *}$ \\
\hline 5 & $\mathrm{MCV} \mathrm{fL}$ & $33.6 \pm 0.97$ & $33.2 \pm 0.81$ \\
\hline 6 & $\mathrm{MCH} \mathrm{pg}$ & $18.2 \pm 1.7$ & $12.3 \pm 0.91^{* * *}$ \\
\hline 7 & $\mathrm{MCHC}$ g/dL & $40.8 \pm 2.9$ & $35.5 \pm 2.30^{* * *}$ \\
\hline
\end{tabular}

*** Statistically significant

Table 3. Mean values of serum biochemical parameters in affected and apparently healthy small ruminants

\begin{tabular}{|c|c|c|c|}
\hline S. No. & Parameters & Normal Group $(\mathbf{n}=\mathbf{1 0 0})$ & Infected Group $(\mathbf{n = 5 0})$ \\
\hline 1 & Total protein g/dL & $36.3 \pm 1.00$ & $37.5 \pm 1.60$ \\
\hline 2 & Albumin g/dL & $2.77 \pm 0.03$ & $2.5 \pm 0.03^{* * *}$ \\
\hline 3 & Globulin g/dL & $4.6 \pm 0.17$ & $4.3 \pm 0.07$ \\
\hline 4 & Cholesterol mg/Dl & $97.0 \pm 3.50$ & $98.9 \pm 2.26$ \\
\hline 5 & Calcitonin mg/dL & $0.76 \pm 0.03$ & $0.78 \pm 0.01$ \\
\hline 6 & Urea mg/dL & $36.3 \pm 1.03$ & $37.5 \pm 1.60$ \\
\hline
\end{tabular}

*** Statistically significant

During current investigation, serum total protein and globulins concentration showed non-significant reduction $(\mathrm{p}>0.05)$ while albumin concentration showed significant decline in animals with Theileria spp. infection compared normal animals (p $<0.05)$. Similar trends of hypoproteinaemia and hypoalbuminaemia was found in small ruminants diseased with theileriosis [36]. The significant decrease in albumin level attributed reduced synthesis of proteins because of liver impairment due to Theileria spp. infection [13]. Moreover lower serum protein concentration could be ascribed due to extravascular amassing of proteinaceous fluids, resulting from diseased lymph nodes [37]. During theileriosis lower serum protein level could be due to shortage of dietary intake, diarrhea and lower production due parasitic infection on the liver [33]. The major sites of synthesis of plasma protein are liver but severe tissue damages in the liver occurs during bovine theileriosis [38]. The decreased serum protein level in animals naturally infected with Theileria spp. infection was due to hypoalbuminaemia and hypoglobulinaemia because of liver damage $[13,27]$. The results of current study revealed non-significant rise in urea level in Theileria spp. infected animals might be endorsed to 
kidney damage [37]. The higher urea level in Theileria spp. infected animals endorsed to histopathologicl variations resulted in the renal parenchyma due to piroplasmosis and shown strong correlation with the level of parasitemia. Non-significant rise in cholesterol level found in animals infected with theileriosis during present study was in accordance to significantly higher level of cholesterol reported in cattle infected with theileriosis [39] but contradicts to [12] who reported non-significant increase of cholesterol levels in small ruminants infected with theileriosis. The higher cholesterol level endorsed to liver impairment due to parallel higher fats contents and lower sugar and protein level [40].

\section{Conclusions}

This is the first preliminary study of Theileria infection in sheep and goats of Multan, southern Punjab, Pakistan which has a deleterious influence health of small ruminants. The current study epitomizes that ovine theileriosis significantly affect the hematological and biochemical parameters in the infected animals that are in the early stage of disease without any appearance of clinical symptoms. Further research is requisite to trace the variations in haematobiochemical parameters due to Theileria spp. infection.

\section{Author's contributions}

Conceived and designed the experiments: $\mathrm{Z}$ Tasawar, Performed the experiments: $M$ Riaz, Analyzed the data: M Riaz, Contributed reagents/ materials/ analysis tools: M Riaz, Wrote the paper: Z Tasawar \& M Riaz.

\section{Acknowledgements}

This current project supported by the Higher Education commission, Islamabad, Pakistan under 5000 indegenous $\mathrm{Ph}$. D. fellowship programme. The authors would like to thank all veterinarians for helping in sample collection. The authors declare that there is no conflict of interest.

\section{References}

1. Radostits OM, Gay CC, Hinchcliff KW \& Constable PD (2007). Veterinary Medicine: A textbook of the diseases of cattle, horse, sheep, pigs and goat. Saunders, 26, pp.1518-1522.

2. Aktas M, Altay K \& Dumanli N (2005). Survey of Theileria parasites of sheep in eastern Turkey using polymerase chain reaction. Sm Rum Re. 60: 289-293.

3. Rymaszewska A \& Grenda S (2008). Bacteria of the genus Anaplasma characteristics of Anaplasma and their vectors: a review. Vet Med 53: 573-584.

4. Telmadarraiy Z, Oshaghi MA, HosseiniVasoukolaei N, Yaghoobi-Ershadi MR, Babamahmoudi F\& Mohtarami F (2012). First molecular detection of Theileria ovis in Rhipicephalus sanguineus ticks in Iran. Asi Pac J Trop Med 5: 29-32.

5. Tageldin MH, Zakia AM, Nagwa ZG \& Sawi SAS (1992). An outbreak of theileriosis in sheep in Sudan. Tropl Ani and Heal Prod 24: 15-16.

6. Sayin F, Nalbantoglu S, Bayram BA, Çkakmak A \& Karer Z (2009). Epidemiological studies on sheep and goat Vheilåria infection. Ank Unii Vet Fak Derisi 56: 120-129.

7. Hong Y, Jianxun L, Guiquan G, Bingyi L, Miling M, Qicai Z, Wenshun L, Chengping L \& Jabbar A (2002). Experiments on transmission of unidentified Theileria sp. to small ruminants with Haemaphysalis qinghaiensis and Hyalomma

anatolicum anatolicum. Vet Parasit 108: 21-30.

8. Tehrani AA, Hosseini E \& Bahrami AM (2013). Biochemical, Hematological studies in cattle naturally infected with Theileria annulata. Bul of Envir Pharm Life Sci 9: 07-10.

9. Almeria SL, Castella D, Ferrer A, Ortuno. A, Estrade- Pena \& Gutierrez JF 
(2001). Bovine piroplasma in Minorca (Baleric Islands Spain) a comparison of PCR-based and light microscopy detection. Vet Parasi 99: 249-259.

10. Inci A, Ica A, Yildirim A \& Duzlu O (2010). Identifica-tion of Babesia and Theileria species in small ruminants in Central Anatolia (Turkey) via re-verse line blotting. Turk J Vet and Ani Sci 34: 205-210.

11. Mal G, Suchitra SD, Kumar R \& Sahani MS (2001). Haemoatological and mineral profile of bacterian and dromedary camel. Ind J Ani Sci 71: 1162-1163

12. Baghshani H, RazmiG R, Yaghfouri S \& Dezaki AA (2011). Investigation of selected biochemical parameters in sheep naturally infected with theileriosis. Comp Clini Pathol 21: 1417-21.

13. Singh A, Singh J, Grewal AS \& Brar RS (2001). Studies on some blood parameters of crossbred calves with experimental Theileria annulata infections. Vet Res Comm 25: 289-300.

14. Zangana IK \& Naqid IA. Prevalence of piroplasmosis (Theileriosis and Babesiosis) among goats in Duhok Governorate. AL-Anbar J Vet Sci 2011; 4: 50-57.

15. Jalali SM, Khaki Z, Kazemi BD, Rahbari S, Shayan, P, Bandehpour M \& Yasini SP (2014). Molecular Detection and Identification of Theileria Species by PCR-RFLP Method in Sheep from Ahvaz, Southern Iran. Iran J Parasitol 9: 99-106.

16. Shaikh RS, Ramzan K, Nazil S, Khan SN \& Riazuddin S (2005). A new locus for non-syndromic deafness DFNB maps to chromosomes 11p13-p12. Ameri J Med and Gen Annals. 138: 392-395.

17. Razavi SM, Nazifi S, Gorjipoor S, Masoudian M \& Ansari-Lari M (2011). Study on acute-phase protein changes and their diagnostic values in malignant ovine theileriosis. Comp Clin Pathol 20: 227-232.

18. Nazifi S, Razavi SM, Kianiamin P \& Rakshandehroo E (2011). Evaluation of erythrocyte antioxidant mechanisms: antioxidant enzymes, lipid peroxidation, and serum trace elements associated with progressive anemia in ovine malignant theileriosis. Parasit Res 109: 275-281.

19. Bell-Sakyi L, Koney EBM, Dogbey O \& Walker AR (2004). Incidence and prevalence of tick-borne haemoparasites in domestic ruminants in Ghana. Vet Parasit 124:25-42.

20. Al-Sultan II, Dawood KA \& Nasir MD (1999). The effect of bovine Theileriasis on proliferation of stem cell and blood cell production. Iraqi J Vet Med 23:134142.

21. Karawan AJ (2007). Study of Theileriosis in cattle and effects of (Butalex®) Buparvaquone. MSc thesis. Collegeof Education, University of Bahgdad. Iraq.

22. Geerts S, Holmes PH, Diall O \& Eisler MC (2001). African bovine theileriosis: The problem of drug resistance. Trends in parasitol 17:25-28.

23. Mehta HK, Sisodia RS \& Misraula RS (1998). Clinical and haematological observation in experimentally induced cases of bovine theileriosis. Ind $\mathrm{J}$ Clin Investig 26: 636-40.

24. Rayulu VC \& Hafeez MD (1995). Haematological values in cattle infected with Theileria annulata. Jour of Ani Sci 65: 1202- 1203.

25. Grewal A, Ahuja CS, Singh P\& Chaudhary KC (2005). Status of lipid peroxidation, some antioxidant enzymes and erythrocytic fragility of crossbred cattle naturally infected with Theileria annuluta. Vet Res Commun 29: 387-394.

26. Omer OH, El-Malik KH, Mahmoud OM, Haroun EM, Hawas A, Sweeney D \& Magzoub M (2002). Haematological 
profiles in pure bred cattle naturally infected with Theileria annulata in Saudi Arabia. Vet Parasitol 107: 161-168.

27. Watarai M, Tobe, T, Yoshikawa M \& Sasakawa C (1995). Contact of Shigella with host cells triggers release of Ipa invasins and is an essential function of invasiveness. EMBO Jou 14: 2461-2470.

28. Yagi Y, Thongnoon $\mathrm{P}$, Shiono $\mathrm{H} \&$ Chikayama Y (2002). Increase in oxidized proteins in Theileria sergentiinfected erythrocyte membrane. $J$ Vet and Med Sci 64: 623-625.

29. Shiono H, Yagi Y, Kumar A \& Yamanaka M (2004). Accelerated binding of autoantibody to red blood cells with increasing anemia in cattle experimentally infected with Theileria sergenti. J Vet Pub Heal 51: 39-42.

30. Ahmed JS (2002). The role of cytokines in immunity and immunopathogenesis of pirolasmosis. Parasit Res 88: 48-50.

31. Campbell JDM, Howie, SEM, Odling KA \& Glass EJ (1995). Theileria annulata induces aberrant $\mathrm{T}$ cell activation in vitro and in vivo. Clin and Exp Immun 99: 203-210).

32. Al-Amery May \& Hasso SA (2002). Laboratory diagnosis of novel species of Theileria hirci, Eimeria caprovina and Eimeria pallida in goats in Iraq. Sm Rum Res 44: 163-166.

33. Al-Obaidi QT \& Al Saad KMA (2004). Haematological and pathological study of sheep naturally infected with Theileria hirci. Iraqi J Vet Sci 18:165175.

34. Yasini S, Khaki Z, Rahbari S, Kazemi B, Amoli JS, Gharabaghi A \& Jalali S (2012).
Hematologic and Clinical Aspects of Experimental Ovine Anaplasmosis Caused by Anaplasma ovis in Iran. Iran J Parasitol 7: 91-96.

35. Sandhu GS, Grewal AS, Singh A, Kondal JK, Singh J \& Brar RS (1998). Haematological and biochemical studies in experimental Theileria annulata infection in crossbred calves. Vet Res Comm 22: 347-354.

36. Hosny AM, Aly SA, \& Ahmed OI (2010). Oxidative stress and some haematobiochemical changes in blood of cattle during theileriosis. Assiut Vet Med Jour 56: 218-238.

37. Col R \& Uslu U (2007). Changes in selected serum components in cattle naturally infected with Theileria annulata. Bulletin of Vet Inst Pulawy 51: 15-18.

38. Yurtseven S \& Uysal H (2009). Decreased serum sialic acid, albuminglobulin ratio and total protein levels in cattle heavily infected with Theileria annulata. Ank Üni Vet Fak Dergi 56:141-144.

39. Shahnawaz S, Ali M, Aslam MA, Fatima R, Chaudhry ZI, Hassan MU, Ali M \& Iqbal F(2011). A Study on the prevalence of a tick transmitted pathogen, Theileria annulata and hematological profile in cattle from Southern Punjab (Pakistan). Parasit Res 109: 1155-1160.

40. Yadav CL \& Sharma NN (1986). Changes in blood chemical components during experimentally induced Theileria annulata infection in cattle. Vet Parasit 21: 91-98. 